\title{
The application of multiple reaction monitoring and multi-analyte profiling to HDL proteins
}

\author{
Hussein N Yassine ${ }^{1 *}$, Angela M Jackson², Chad R Borges ${ }^{3}$, Dean Billheimer ${ }^{4}$, Hyunwook Koh ${ }^{1}$, Derek Smith ${ }^{3}$, \\ Peter Reaven ${ }^{5}$, Serrine S Lau ${ }^{6}$ and Christoph H Borchers ${ }^{2,7}$
}

\begin{abstract}
Background: HDL carries a rich protein cargo and examining HDL protein composition promises to improve our understanding of its functions. Conventional mass spectrometry methods can be lengthy and difficult to extend to large populations. In addition, without prior enrichment of the sample, the ability of these methods to detect low abundance proteins is limited. Our objective was to develop a high-throughput approach to examine HDL protein composition applicable to diabetes and cardiovascular disease (CVD).
\end{abstract}

Methods: We optimized two multiplexed assays to examine HDL proteins using a quantitative immunoassay (Multi-Analyte Profiling- MAP) and mass spectrometric-based quantitative proteomics (Multiple Reaction Monitoring-MRM). We screened HDL proteins using human XMAP (90 protein panel) and MRM (56 protein panel). We extended the application of these two methods to HDL isolated from a group of participants with diabetes and prior cardiovascular events and a group of non-diabetic controls.

Results: We were able to quantitate $69 \mathrm{HDL}$ proteins using MAP and 32 proteins using MRM. For several common proteins, the use of MRM and MAP was highly correlated $(p<0.01)$. Using MAP, several low abundance proteins implicated in atherosclerosis and inflammation were found on HDL. On the other hand, MRM allowed the examination of several HDL proteins not available by MAP.

Conclusions: MAP and MRM offer a sensitive and high-throughput approach to examine changes in HDL proteins in diabetes and CVD. This approach can be used to measure the presented HDL proteins in large clinical studies.

Keywords: High density lipoprotein, Proteomics, Multiple reaction monitoring, Multi-analyte panel, Diabetes, Cardiovascular disease

\section{Introduction}

Recent findings suggest that HDL carries over 80 proteins involved in lipid metabolism, complement regulation, acute phase response and proteinase inhibition [1]. This protein cargo appears to be remodeled in metabolic syndrome [2], cardiovascular disease [1,3] and after cholesterol therapies [4]. However, measurement of proteins associated with lipids and that span several orders of magnitude in abundance can be challenging. Conventional LC-MS/MS assays and label-free quantitation methods using spectral counting or extracted ion chromatograms (XIC) used in the previous studies [1-4] can be lengthy

\footnotetext{
* Correspondence: hyassine@usc.edu

${ }^{1}$ Department of Medicine, University of Southern California, Los Angeles, CA, USA

Full list of author information is available at the end of the article
}

and are limited to small sample sizes. Multiple Reaction Monitoring (MRM), on the other hand, is a tandem MS (MS/MS) scan mode unique to triple quadrupole MS instrumentation that is capable of rapid, sensitive, and specific quantitation of peptides in highly complex sample matrices, such as plasma [5,6]. MRM is a targeted approach that requires knowledge of the molecular weight the peptide of interest and its fragmentation pattern, leading to the generation of target "transitions" for monitoring protein levels. When coupled with stable isotope peptide standards (SIS peptides), quantitation using MRM can be highly reproducible [7]. MRM quantitation has been successfully applied to plasma proteins [5,6] and, more recently, to a limited subset of HDL proteins [8]. Without pre analytical depletion or enrichment, MRM sensitivity can be compromised by the 
existence of high abundance proteins. Although the sensitivity of MRM allows analyses at levels down to one $\mathrm{ng} / \mathrm{mL}$, the accuracy at the lower end of the abundance range can be problematic. In this case, the use of methods that deplete the higher abundance proteins is often needed. These methods, however, can lead to the unintentional removal of proteins that are attached to the depleted proteins. An alternative approach is the use of immunoassays that offer much improved sensitivity. One example of these assays is multiplexed immunoassay panels (MAP). MAP compliments MRM at this low end and helps ensure that proteins are fully and correctly quantitated at the low range.

There has been considerable interest in understanding HDL functions in light of the strong inverse association of HDL cholesterol and cardiovascular disease (CVD) and the lack of improved CVD outcomes after raising HDL's cholesterol content in three recent trials [9-11]. Knowledge of HDL protein composition promises to improve our understanding of HDL's multiple functions in CVD. In this study, we optimized two approaches to measure HDL proteins using multiplexed immunoassays (Multi-Analyte Profiling-MAP) and quantitative proteomics (MRM) platforms. We extended the application of these two techniques to HDL isolated from participants with and without diabetes and CVD. Our findings suggest that MAP can be used to monitor low abundance proteins on HDL, whereas MRM allows examining higher abundance HDL proteins without the need for pre-existing antibodies.

\section{Materials and methods Clinical samples}

The study was approved by the University of Arizona Institutional Review Board, and all patients provided written informed consent prior to testing. The samples were collected at University of Arizona Medicine Clinics. Participants reported to the Center for Clinical and Translational Sciences (CaTS) after an overnight fast. Samples were collected in EDTA containing tubes. The presence of cardiovascular disease was defined by a prior history of coronary artery bypass surgery (CABG), percutaneous transluminal angioplasty (PTCA), prior MI, or thrombotic stroke. Patients were older than 18 years of age. New diagnosis of diabetes was based on 2 hour oral glucose tolerance test (OGTT) $>200 \mathrm{mg} / \mathrm{dl}$ or glycated hemoglobin $(\mathrm{HbA} 1 \mathrm{c}>6.5 \%)$. Established diabetes was defined by clinical history. The study included disease free participants and participants with advanced kidney disease, diabetes and CVD. The study excluded subjects if they met any of the following criteria: had type had 1 diabetes, were on an active weight loss program, history of cancer, HIV, or steroid use.

\section{HDL Isolation technique}

HDL isolation by centrifugation was based on a modification of a previously published protocol [1]. In brief, potassium bromide ( $\mathrm{KBr} \sim 55 \mathrm{mg}$ ) was added to $310 \mu \mathrm{l}$ of plasma samples to create a density of $1.21 \mathrm{~g} / \mathrm{mL}$. The sample was overlaid with $200 \mu \mathrm{L}$ of $1.21 \mathrm{~g} / \mathrm{mL}$ density solution for a total volume was $500 \mu \mathrm{L}$. Samples were then spun at $120,000 \mathrm{rpm}$, at $16^{\circ} \mathrm{C}$ for 2 hours (Beckman TLX ultracentrifuge with a type 120.1 fixed angle rotor using thick-walled $500 \mu \mathrm{L}$ Polycarbonate tubes, item 343776). The upper $125 \mu \mathrm{L}$ solution that had a density of less than $1.21 \mathrm{~g} / \mathrm{mL}$ was removed and $150 \mu \mathrm{L}$ of $\mathrm{NaCl} /$ EDTA solution $(0.9 \%(\mathrm{w} / \mathrm{v}) \mathrm{NaCl}, 0.1 \%(\mathrm{w} / \mathrm{v})$ EDTA, $\mathrm{pH}$ 7.4) was added to each tube for a final density of $1.063 \mathrm{~g} / \mathrm{mL}$. Subsequently, $225 \mu \mathrm{L}$ of $1.06 \mathrm{KBr}$ solutions in $\mathrm{NaCl} / \mathrm{EDTA}$ was underlaid with a final volume of $500 \mu \mathrm{L}$ for a second 2 hour spin at the same parameters listed. The bottom $125 \mu \mathrm{L}$ (HDL fraction) of solution was removed for further analysis. Four HDL samples were sent to Myriad RBM to externally validate our measurements using an immunoassay in a CLIA certified laboratory. To confirm depletion of albumin and apoB proteins from HDL samples, HDL from a CVD pool was isolated with a second approach that involved long centrifugations at two sequential spins each of 10 hours duration using the above technique. Albumin levels were then measured using a commercial ELISA (Assaypro).

\section{Measurements of HDL proteins}

We screened HDL using the human MAP panel (90 proteins) and MRM panel (56 proteins). The proteins that were detected on HDL are summarized in Table 1. Four HDL samples were used to compare protein measures by MAP and MRM. Subsequently, two pools of HDL samples (each pool $500 \mu \mathrm{L}$ combined from $10 \mathrm{HDL}$ isolates) - one pooled from ten non-diabetic subjects defined as the control group and a second pooled from ten subjects with both diabetes and CVD-defined as the disease group were run on the MAP platform using the HumanMAP panel and by MRM.

\section{MAP}

The samples were analyzed at Myriad RBM that uses Luminex xMAP. Luminex xMAP is a well-established particle array system that is based on beads with unique fluorescent signatures with proprietary multi-analyte panel targets assessed for cross-reactivity. This technology has been used for the detection of numerous targets, such as cytokines [12], cancer markers [13], and indicators for various disease states [14]. The assay details of this platform are well described in Myriad RBM website (www. myriadrbm.com). Here we applied MAP to HDL samples obtained by ultracentrifugation in both $2 \times 2$ and $10 \times 10$ isolation techniques, calculating the limit of detection and the recovery analysis after 12 dilutions. The data is 
Table 1 Proteins that were quantified on HDL from the healthy and diseased sample pool

\begin{tabular}{|c|c|c|c|}
\hline \multicolumn{2}{|l|}{ MAP (69 proteins quantified out of 90 ) } & \multicolumn{2}{|c|}{ MRM (32 proteins quantified out of 56 ) } \\
\hline Protein & Uniprot ID & ID & Uniprot ID \\
\hline C-Reactive Protein (CRP) & P02741 & Apolipoprotein D & P05090 \\
\hline von Willebrand Factor (vWF) & P04275 & Apolipoprotein A-I & P02647 \\
\hline Adiponectin & Q15848 & Apolipoprotein A-II precursor & P02652 \\
\hline Fibrinogen & P02671, P02675, P02679 & Apolipoprotein A-IV & P06727 \\
\hline Serum Amyloid P-Component (SAP) & P02743 & Apolipoprotein B-100 & P04114 \\
\hline Sex Hormone-Binding Globulin (SHBG) & P04278 & Apolipoprotein C-I lipoprotein & P02654 \\
\hline Immunoglobulin A (IgA) & P44969 & Apolipoprotein C-III & P02656 \\
\hline Complement C3 (C3) & P01024 & Apolipoprotein E & P02649 \\
\hline Protein S & P26447, P06703 & Apolipoprotein L1 & O14791 \\
\hline Thrombospondin-1 & P07996 & Beta-2-glycoprotein I_Apo H & P02749 \\
\hline Haptoglobin & P00738 & Apolipoprotein C-II & P02655 \\
\hline Complement factor $\mathrm{H}$ & P08603 & Apolipoprotein(a) & P08519 \\
\hline Ferritin (FRTN) & P02794, P02792 & Apolipoprotein M & O95445 \\
\hline Alpha-2-Macroglobulin (A2Macro) & P01023 & PON 1 & P27169 \\
\hline Myeloperoxidase (MPO) & P05164 & Albumin & P02768 \\
\hline Plasminogen Activator Inhibitor 1 (PAI-1) & P05121 & Alpha-1-Anti-trypsin & P01009 \\
\hline Tumor Necrosis Factor Receptor 2 (TNFR2) & P20333 & Alpha-1B-glycoprotein & P04217 \\
\hline Insulin & P01308 & Alpha-2-antiplasmin & P08697 \\
\hline Vitronectin & P04004 & Alpha-2-HS-glycoprotein & P02765 \\
\hline Calcitonin & P01258 & Clusterin & P10909 \\
\hline Beta-2-Microglobulin (B2M) & P61769 & Complement $\mathrm{C} 1$ inactivator & P05155 \\
\hline CD5L & O43866 & Complement C3 & P01024 \\
\hline Intercellular Adhesion Molecule 1 (ICAM-1) & P05362 & Complement $\mathrm{C} 4$ beta chain & POCOL5 \\
\hline CD 40 antigen (CD40) & Q6P2H9 & Complement C4 gamma chain & POCOL5 \\
\hline Carcinoembryonic Antigen (CEA) & P06731 & Complement C9 & P02748 \\
\hline Vascular Endothelial Growth Factor (VEGF) & P15692 & Complement factor $\mathrm{H}$ & P08603 \\
\hline Thyroxine-Binding Globulin (TBG) & P05543 & Fibrinogen alpha chain & P02671 \\
\hline Vascular Cell Adhesion Molecule-1 (VCAM-1) & P19320 & Fibrinogen beta chain & P02675 \\
\hline Thyroid-Stimulating Hormone (TSH) & P01215, P01222 & Fibrinogen gamma chain & P02679 \\
\hline Brain-Derived Neurotrophic Factor (BDNF) & P23560 & Fibrinopeptide A & P02671 \\
\hline Matrix Metalloproteinase-3 (MMP-3) & P08254 & Haptoglobin beta chain & P00738 \\
\hline Fatty Acid-Binding Protein, heart (FABP, heart) & P05413 & Hemopexin & P02790 \\
\hline Tissue Inhibitor of Metalloproteinases 1 (TIMP-1) & P01033 & Heparin cofactor II & P05546 \\
\hline Myoglobin & P02144 & Kininogen-1 & P01042 \\
\hline Immunoglobulin M (IGM) & P01871 & L-selectin & P14151 \\
\hline Interleukin-8 (IL-8) & P10145 & & \\
\hline Interleukin-1 beta (IL-1 beta) & P01584 & & \\
\hline EN-RAGE & P80511 & & \\
\hline Interleukin-1 alpha (IL-1 alpha) & P01583 & & \\
\hline Monocyte Chemotactic Protein 1 (MCP-1) & P13500 & & \\
\hline Macrophage Inflammatory Protein-1 beta (MIP-1 beta) & P13236 & & \\
\hline Alpha-1-Antitrypsin (AAT) & P01009 & & \\
\hline Fetuin A (alpha HS-glycoprotein) & P02765 & & \\
\hline
\end{tabular}


Table 1 Proteins that were quantified on HDL from the healthy and diseased sample pool (Continued)

\begin{tabular}{|c|c|}
\hline Interleukin-15 (IL-15) & P40933 \\
\hline Epidermal Growth Factor (EGF) & P01133 \\
\hline Apolipoprotein D (Apo D) & P05090 \\
\hline Eotaxin-1 & P51671 \\
\hline Apolipoprotein(a) (Lp(a)) & P08519 \\
\hline Macrophage-Derived Chemokine (MDC) & 000626 \\
\hline Clusterin (CLU) & P10909 \\
\hline Prostate-Specific Antigen, Free (PSA-f) & P07288 \\
\hline Apolipoprotein A-I (Apo A-I) & P02647 \\
\hline Leptin & P41159 \\
\hline Matrix Metalloproteinase-9 (MMP-9) & P14780 \\
\hline Interleukin-10 (IL-10) & P22301 \\
\hline Interleukin-18 (IL-18) & Q14116 \\
\hline Interleukin-2 (IL-2) & P60568 \\
\hline Lymphotactin & P47992 \\
\hline T-Cell-Specific Protein RANTES (RANTES) & P13501 \\
\hline Erythropoietin (EPO) & P01588 \\
\hline Serum Glutamic Oxaloacetic Transaminase (SGOT) & P17174 \\
\hline Apolipoprotein E (Apo E) & P02649 \\
\hline Epithelial-Derived Neutrophil-Activating Protein 78 (ENA-78) & P42830 \\
\hline Stem Cell Factor (SCF) & P21583 \\
\hline Interleukin-13 (IL-13) & P35225 \\
\hline Apolipoprotein B (Apo B) & P04114 \\
\hline Growth Hormone (GH) & P01241 \\
\hline Interleukin-4 (IL-4) & P05112 \\
\hline Interleukin-1 receptor antagonist (IL-1 ra) & P18510 \\
\hline
\end{tabular}

presented in Additional file 1: Table S1. MAP was then applied to the control and disease HDL sample pool.

\section{MRM}

The samples were analyzed at the University of Victoria Genome BC Proteomics Centre with a dedicated core service for MRMs with the capacity of high throughput stable isotope peptide production for absolute quantification. We screened HDL protein using existing published transitions that were previously applied to plasma proteins [6] or to newly developed transitions from proteins that are associated with HDL (LCAT, CETP, PLTP, PON1, Apolipoprotein D, Apolipoprotein M, Apolipoprotein L1, Apolipoprotein CII) or of interest to CVD (Macrophage migration inhibitory factor, Matrix Gla protein). The transition list used is provided in Additional file 1: Table S2. For the generation of CV data, the samples were injected four times per method, with two methods in total. The total number of transitions per sample was 142 (method 1-low abundant specific targets) +88 (method 2-general high abundance plasma protein targets). There were between 1-5 transitions monitored for each peptide. Proteins with new transitions, or those that were low in abundance were monitored using either multiple peptides (as CETP, MIF, PON1) or up to 5 transitions per peptide. The methods were not scheduled as the retention times shifted between HDL isolation procedures that can result in non-quantifiable data. Based on these replicate runs, we selected one transition for quantitation analysis based on the lowest coefficient of variation by the 4 replicate "technical" runs. These transitions are summarized in Table 2. The selection process of these transitions (to exclude interferences or amino acid modifications such as phosphorylation and glycosylation) was previously described $[6,15]$ in detail and included in the (Additional file 1: MRM methods). Representative chromatograms of the healthy pool HDL transitions and disease pool HDL transitions are also included in the figure Additional file 1: Figure S1. 
Table 2 HDL peptides selected for MRM

\begin{tabular}{|c|c|c|c|c|}
\hline Mass info (Q1/Q3) & Protein & Peptide sequence & Fragment ion & $\% C V(n=8)$ \\
\hline $575.3 / 937.5$ & Albumin & LVNEVTEFAK & y8 & 5.3 \\
\hline $555.8 / 797.4$ & Alpha-1-Anti-trypsin & LSITGTYDLK & y7 & 23.9 \\
\hline $656.8 / 771.4$ & Alpha-2-antiplasmin & LGNQEPGGQTALK & y8 & 116.2 \\
\hline 399.5/490.3 & Alpha-2-HS-glycoprotein & HTLNQIDEVK & $\mathrm{y} 4$ & 33.6 \\
\hline $437.2 / 540.3$ & Antithrombin-III & DDLYSDAFHK & $y++9$ & 63.2 \\
\hline 409.3/599.4 & Apolipoprotein M & AFLLTPR & y5 & 6.4 \\
\hline $405.9 / 572.8$ & Apolipoprotein A-I & ATEHLSTLSEK & $\mathrm{y} 10++$ & 1.2 \\
\hline $486.8 / 443.2$ & Apolipoprotein A-II precursor & SPELQAEAK & $y++8$ & 4.5 \\
\hline $524.3 / 450.8$ & Apolipoprotein B-100 & FPEVDVLTK & $y++8$ & 20.7 \\
\hline $516.8 / 466.2$ & Apolipoprotein C-I lipoprotein & TPDVSSALDK & $y++9$ & 5.4 \\
\hline $519.3 / 666.3$ & Apolipoprotein C-II & TAAQNLYEK & y5 & 3.4 \\
\hline $598.8 / 244.1$ & Apolipoprotein C-III & GWVTDGFSSLK & b2 & 14.2 \\
\hline $436.3 / 659.3$ & Apolipoprotein D & VLNQELR & y5 & 6.5 \\
\hline $484.8 / 588.3$ & Apolipoprotein E & LGPLVEQGR & y5 & 2.1 \\
\hline $815.9 / 651.3$ & Apolipoprotein L1 & VTEPISAESGEQVER & $y++12$ & 26.7 \\
\hline $786.5 / 535.3$ & Apolipoprotein (a) & LFLEPTQADIALLK & $y++10$ & 45.1 \\
\hline $511.8 / 751.4$ & Beta-2-glycoprotein I_Apo H & ATWYQGER & y6 & 42.6 \\
\hline $644.8 / 602.3$ & Clusterin & ELDESLQVAER & y5 & 45.6 \\
\hline $501.8 / 731.4$ & Complement C3 & TGLQEVEVK & y6 & 50.8 \\
\hline $557.8 / 629.4$ & Complement $\mathrm{C} 4$ beta chain & VDGTLNLNLR & y5 & 89.9 \\
\hline $362.9 / 487.3$ & Complement C4 gamma chain & ITQVLHFTK & $y++8$ & 16.1 \\
\hline $508.6 / 494.3$ & Complement C9 & TEHYEEQIEAFK & $y 4$ & 44.3 \\
\hline 671.4/830.4 & Complement factor $\mathrm{H}$ & SPDVINGSPISQK & y8 & 63.0 \\
\hline $570.8 / 867.5$ & Fibrinogen alpha chain & GSESGIFTNTK & y8 & 50.1 \\
\hline $497.9 / 600.3$ & Fibrinogen gamma chain & YEASILTHDSSIR & $y++11$ & 17.3 \\
\hline 768.8/1077.5 & Fibrinopeptide A & ADSGEGDFLAEGGGVR & $\mathrm{y} 11$ & 95.1 \\
\hline $490.8 / 562.3$ & Haptoglobin beta chain & VGYVSGWGR & y5 & 59.9 \\
\hline 610.8/480.3 & Hemopexin & NFPSPVDAAFR & $y++9$ & 147.9 \\
\hline $514.8 / 814.4$ & Heparin cofactor II & TLEAQLTPR & y7 & 31.9 \\
\hline 626.3/1051.5 & Kininogen-1 & TVGSDTFYSFK & y9 & 28.9 \\
\hline 497.8/794.4 & L-selectin & AEIEYLEK & y6 & 64.4 \\
\hline $592.8 / 943.5$ & PON 1 & IQNILTEEPK & y8 & 51.0 \\
\hline
\end{tabular}

HDL proteins that were quantified using MRM. The CV was calculated using 4 technical runs.

\section{Statistical analysis}

We used the statistical program R2.1 ( $\mathrm{R}$ core development team). The characteristics of the two pools were compared using an independent sample test or a proportion test. The correlation coefficient and the $\mathrm{p}$ value generated between plasma proteins and HDL proteins was obtained using spearman correlation test.

\section{Results and discussion}

\section{Description of study participants}

The goal of this project was to use sensitive and high throughout approach to analyze HDL proteins in health and vascular disease such as diabetes and CVD. The samples were selected to detect differences in HDL proteins between healthy controls and patients with chronic vascular disease. The study demographics and biochemical measurements are listed in Table 3. The two groups were age and sex matched. All diseased individuals had a history of CVD events prior to participation. As shown in Table 3, diseased subjects were obese, with lower HDL cholesterol, elevated triglyceride levels, uncontrolled diabetes, elevated inflammation (CRP), and evidence of chronic kidney disease as revealed by the elevated plasma creatinine. 
Table 3 Demographic and biochemical characteristics of study participants

\begin{tabular}{lccc}
\hline & Control $(\mathbf{n}=\mathbf{1 0})$ & Disease $(\mathbf{n}=10)$ & p value \\
\hline Age (yrs) & $58.4(6.1)$ & $62.2(7.5)$ & 0.233 \\
Sex ( M:F) & $4: 6$ & $5: 5$ & 0.99 \\
BMI (kg/ m²) & $24.3(4.5)$ & $37.8(7.7)$ & 0.001 \\
Systolic BP (mm Hg) & $122.4(9.4)$ & $131.4(17.4)$ & 0.173 \\
Diastolic BP (mmHg) & $74.8(5.7)$ & $70.7(9.8)$ & 0.275 \\
LDL (mg/dL) & $138.5(35)$ & $114.1(42.2)$ & 0.178 \\
HDL (mg/dL) & $58.7(9.5)$ & $36.1(7.46)$ & $<0.001$ \\
CRP (mg/dL) & $2.6(2.27)$ & $13.3(11)$ & 0.014 \\
Triglycerides ( mg/dL) & $111.1(55)$ & $309.2(205)$ & 0.014 \\
Creatinine (mg/dL) & $0.7(0.15)$ & $1.65(0.93)$ & 0.011 \\
Glycated Hemoglobin \% & $5.4(0.38)$ & $9.2(2.71)$ & 0.002 \\
Urine Microalbumin & $8.4(6.7)$ & $1667.5(2596)$ & 0.114 \\
(mcg/mg creatinine) & & &
\end{tabular}

The samples were pooled from the control and disease groups. Values are means (SD).

\section{HDL and Plasma proteins}

One challenge in HDL proteomics is differentiating whether proteins are actually present within HDL or are predominately carried within plasma and have become loosely associated with HDL before or during the isolation procedure. We initially isolated HDL using a two sequential spins $(2 \mathrm{hrs} \times 2)$ and we are able to detect several low abundance proteins commonly associated with atherogenesis and inflammation using MAP (Table 1) of participants with both diabetes and CVD. To confirm whether these proteins are part of the HDL fraction or loosely attached plasma proteins, a longer centrifugation process was employed to isolate HDL $(10 \mathrm{hrs} \times 2)$. Plasma albumin levels were determined to be $45 \mathrm{mg} / \mathrm{mL}$. After the $(2 \mathrm{hrs} \times 2)$ centrifugation, albumin levels within the HDL fraction were $0.1 \mathrm{mg} / \mathrm{mL}$. After prolonged sequential centrifugation step $(10 \mathrm{hrs} \times 2)$, albumin levels were below the detection limits of this assay. Proteins detectable on HDL (by both centrifugation techniques) assessed by MAP, along with plasma protein concentrations are summarized in Table 4. We then correlated the concentrations of these proteins between the different fractions. We found no correlation between plasma and HDL proteins identified in either the $(2 \mathrm{hrs} \times 2)$ or $(10 \mathrm{hrs} \times 2)$ HDL isolation preparations. For example, Apo A-I concentrations of $0.36,0.27,0.18 \mathrm{mg} / \mathrm{mL}$ in plasma HDL $(2 \mathrm{hrs} \times 2)$ and HDL $(10$ hrs $\times 2)$, respectively shows clear retention on HDL compared to fibrinogen with concentrations of 4.7, $0.0021,0.0012 \mathrm{mg} / \mathrm{mL}$. These findings confirm that non-HDL proteins were efficiently depleted with the longer centrifugation. In contrast, the HDL proteins isolated with the $(2 \mathrm{hrsx} 2)$ and $(10 \mathrm{hrs} \times 10)$ methods were highly correlated (Figure 1, r $=0.95, \mathrm{p}<0.001$ ). As
Table 4 Concentrations of Plasma and HDL proteins from the pooled sample of the diseased subject $(\mathrm{mg} / \mathrm{mL})$

\begin{tabular}{|c|c|c|c|}
\hline Protein & Plasma & HDL $2 \times 2$ & $\begin{array}{l}\mathrm{HDL} \\
10 \times 10\end{array}$ \\
\hline Apolipoprotein A-I (Apo A-I) & 0.36 & 0.259 & 0.178 \\
\hline Alpha-1-Antitrypsin (AAT) & 1.5 & 0.0688 & 0.00736 \\
\hline Immunoglobulin A (IgA) & 2.5 & 0.00422 & 0.00054 \\
\hline Immunoglobulin M (IGM) & 2.1 & 0.00275 & 0.00117 \\
\hline Complement C3 (C3) & 1.5 & 0.00211 & 0.000792 \\
\hline Fibrinogen & 4.7 & 0.00209 & 0.00118 \\
\hline Haptoglobin & 2.3 & 0.00191 & 0.000438 \\
\hline Alpha-2-Macroglobulin & 1.9 & 0.000857 & 0.00104 \\
\hline Apolipoprotein (a) (Lp (a)) & 0.684 & 0.108 & 0.081 \\
\hline Fetuin-A & 0.2 & 0.068 & 0.015 \\
\hline Complement Factor H & 0.1 & 0.057 & 0.0036 \\
\hline Apolipoprotein D (Apo D) & 0.05 & 0.041 & 0.018 \\
\hline Apolipoprotein C-III (Apo C-III) & 0.07 & 0.039 & 0.028 \\
\hline Apolipoprotein B (Apo B) & 1.0 & 0.028 & 0.01 \\
\hline Apolipoprotein H (Apo H) & 0.246 & 0.016 & 0.00091 \\
\hline Vitronectin & 0.26 & 0.013 & 0.0018 \\
\hline Apolipoprotein E (Apo E) & 0.04 & 0.0074 & 0.0042 \\
\hline Clusterin (CLU) & 0.37 & 0.0042 & 0.0011 \\
\hline Thyroxine-Binding Globulin (TBG) & 0.044 & 0.0025 & 0.00033 \\
\hline Beta-2-Microglobulin & 0.0041 & 0.00094 & 0.00033 \\
\hline Vitamin K-Dependent Protein S & 0.05 & 0.00027 & 0.000074 \\
\hline Serum Amyloid P-Component & 0.017 & 0.00015 & 0.000051 \\
\hline C-Reactive Protein (CRP) & 0.015 & 0.00013 & 0.000023 \\
\hline CD5 (CD5L) & 0.00053 & 0.000106 & 0.0000096 \\
\hline $\begin{array}{l}\text { Vascular Cell Adhesion Molecule-1 } \\
\text { (VCAM-1) }\end{array}$ & 0.000761 & 0.000039 & 0.000011 \\
\hline Myoglobin & 0.00013 & 0.000031 & 0.000016 \\
\hline $\begin{array}{l}\text { Tissue Inhibitor of Metalloproteinases } \\
1 \text { (TIMP-1) }\end{array}$ & 0.000104 & 0.0000097 & 0.0000012 \\
\hline Thrombospondin-1 & 0.00482 & 0.000008 & 0.0000036 \\
\hline $\begin{array}{l}\text { Plasminogen Activator Inhibitor } \\
1 \text { (PAl-1) }\end{array}$ & 0.000072 & 0.000004 & 0.0000005 \\
\hline $\begin{array}{l}\text { Tumor Necrosis Factor Receptor } \\
2 \text { (TNFR2) }\end{array}$ & 0.000014 & 0.0000017 & 0.0000001 \\
\hline $\begin{array}{l}\text { T-Cell-Specific Protein RANTES } \\
\text { (RANTES) }\end{array}$ & 0.0000097 & 0.0000015 & 0.0000004 \\
\hline EN-RAGE & 0.000067 & 0.0000001 & $<$ LOW $>$ \\
\hline Myeloperoxidase (MPO) & 0.00183 & $<\mathrm{LOW}>$ & 0.000019 \\
\hline $\begin{array}{l}\text { Sex Hormone-Binding Globulin } \\
\text { (SHBG) }\end{array}$ & 0.0016195 & 0.0000218 & 0.0000006 \\
\hline
\end{tabular}

HDL 2.2 and 10.10 refer to two sequential ultra-centrifugations 2 or 10 hours each. Samples were diluted 12 times and were run once at each dilution. The reported concentrations were in the linear range of the assay (Additional file 1 : Table S1). The strength of this technique is in the ability to measure these HDL proteins across a wide concentration range. 


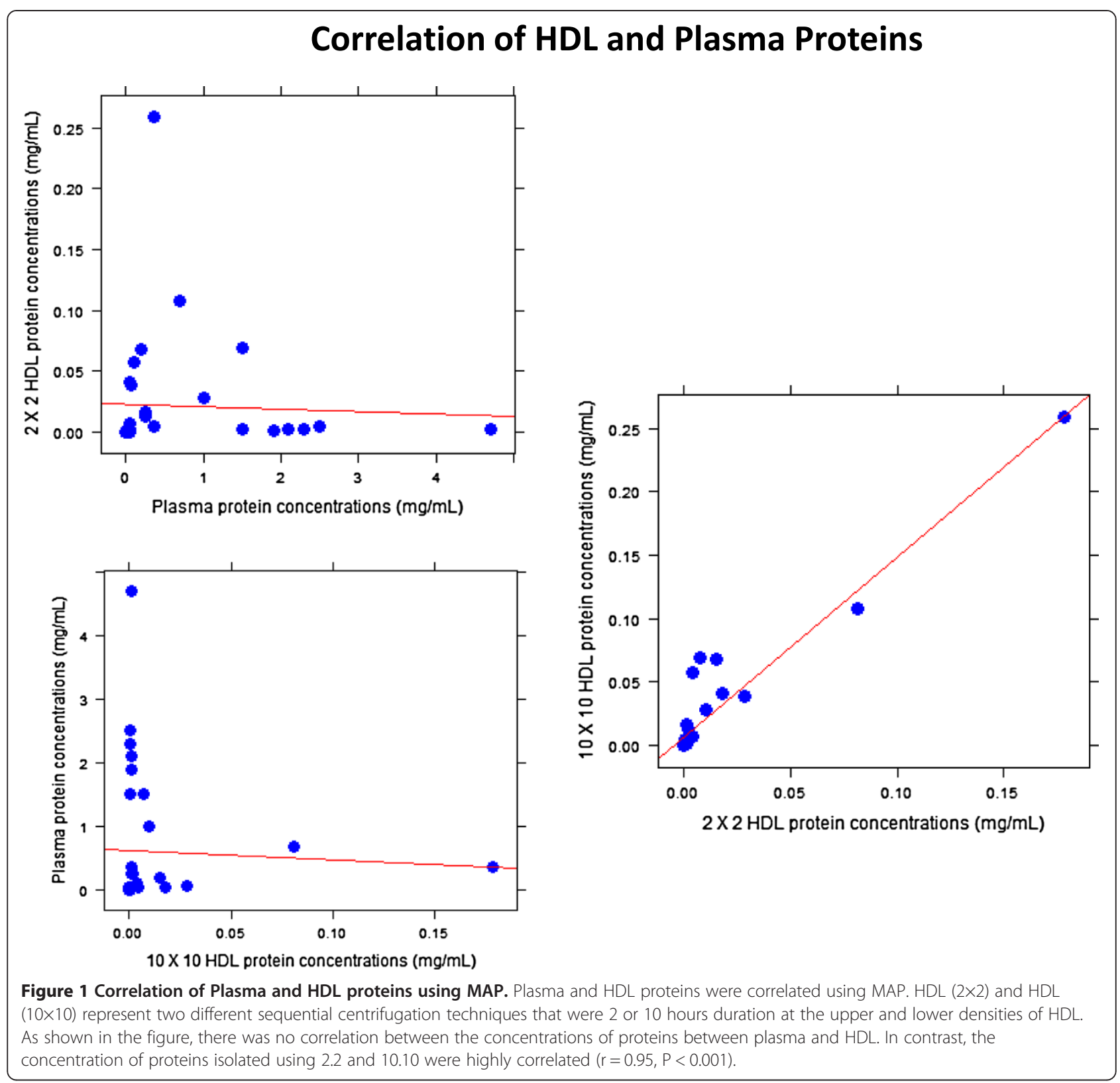

expected the concentrations of HDL proteins were greater in the $(2 \mathrm{hrs} \times 2)$ than the $(10 \mathrm{hrs} \times 2)$ technique (Table 3). The concentration of Apo A-I in plasma was low in this sample pool from diseased participants compared to healthy controls. Published Apo A -I levels are in the $0.9-1.6 \mathrm{mg} / \mathrm{mL}$ range. This may suggest significant HDL remodeling in advanced vascular disease.

\section{Correlation of MAP and MRM}

MRM's performance for low abundance proteins is limited without prior enrichment. Thus, MAP allows the measurements of low abundance proteins on HDL. There were 10 proteins common to both MAP and MRM, however, one protein (Apo E) was not detected in our samples in 3 out of 4 samples by analyzed by MRM. We correlated 9 proteins measured by both approaches in 4 HDL samples. The results are summarized in Table 5 . We did not observe a good correlation for lipoprotein (a), Apo D and Apo CIII between the two methods. Most of Lipoprotein (a) is associated with LDL and present in low abundance on HDL [16] reflecting a challenge for measuring this protein on HDL by MRM. Apo D on the other hand, has a high degree of homology to retinol binding protein or other members of the alpha 2 microglobulin protein superfamily [17]. This might potentially pose a challenge for the MAP technique. Apo CIII was another protein that was measured by MAP and MRM with a weak correlation between the two measurement platforms. It is not clear 
Table 5 Correlation between MRM and MAP (Spearman)

\begin{tabular}{lcc}
\hline Protein & $\mathbf{R}$ & P value \\
\hline Apolipoprotein A-I (Apo A-l) & 0.99 & 0.001 \\
Fetuin-A & 0.97 & 0.03 \\
Apolipoprotein H (Apo H) & 1 & 0.001 \\
Clusterin (CLU) & 1 & 0.008 \\
Apo B & 0.99 & 0.002 \\
Lipoprotein (a) & 0.8 & 0.2 \\
Complement factor H & 0.99 & 0.001 \\
Apo D & -0.2 & 0.5 \\
Apo CIII & -0.06 & 0.9 \\
\hline
\end{tabular}

The correlation between Myriad and MRM was based on the concentration of common protein targets from the $4 \mathrm{HDL}$ samples. There were 10 common proteins between MAP and MRM. Apo E was not detectable in 3 out of the 4 samples by MRM and thus was not included in this list. For most of the common proteins, the two assays were highly correlated.

why these assays were discordant. It is possible that the peptide used is not a good surrogate of Apo CIII levels. Given that Apo CIII exists in multiple isoforms [18], both assays could be measuring different forms.

\section{HDL Proteome in diabetes and CVD}

There is strong inverse association of HDL cholesterol and cardiovascular disease (CVD). However, recent studies suggested that niacin or CETP inhibition designed to raise
HDL-C content did not lead to improved CVD outcomes [9-11]. This discrepancy highlights the need to revise our view of HDL and its functions. One previous study demonstrated that HDL acquires an inflammatory phenotype in acute coronary syndrome [3]. Our results suggest that examining HDL by MAP and MRM can reveal important insights into its biology. One significant finding in our study is the ability to detect for the first time important proposed mediators of atherosclerosis (ENRAGE, MPO, and PAI-1) on HDL using MAP. We also optimized an MRM transition library for the high throughput monitoring of HDL peptides. To investigate the HDL proteome in CVD, HDL-containing samples from 10 non-diabetic participants and HDL from subjects with both diabetes and prior CVD events were pooled into a control and a DM/ CVD sample pool. 69 out of the 90 humanMAP proteins showed acceptable recovery in response to multiple dilutions (Additional file 1: Table S1) and were above the lower limit of detection in both sample pools. Figure 2 represents the ratio of the 69 proteins on HDL between disease and control participants. Our findings suggested that several atherosclerosis-associated and inflammatory proteins were increased on HDL of diseased individuals. In addition, MPO, PAI-1, IL1beta, and ENRAGE were only detected on HDL of diseased individuals. We acknowledge that by pooling the samples, the clinical utility

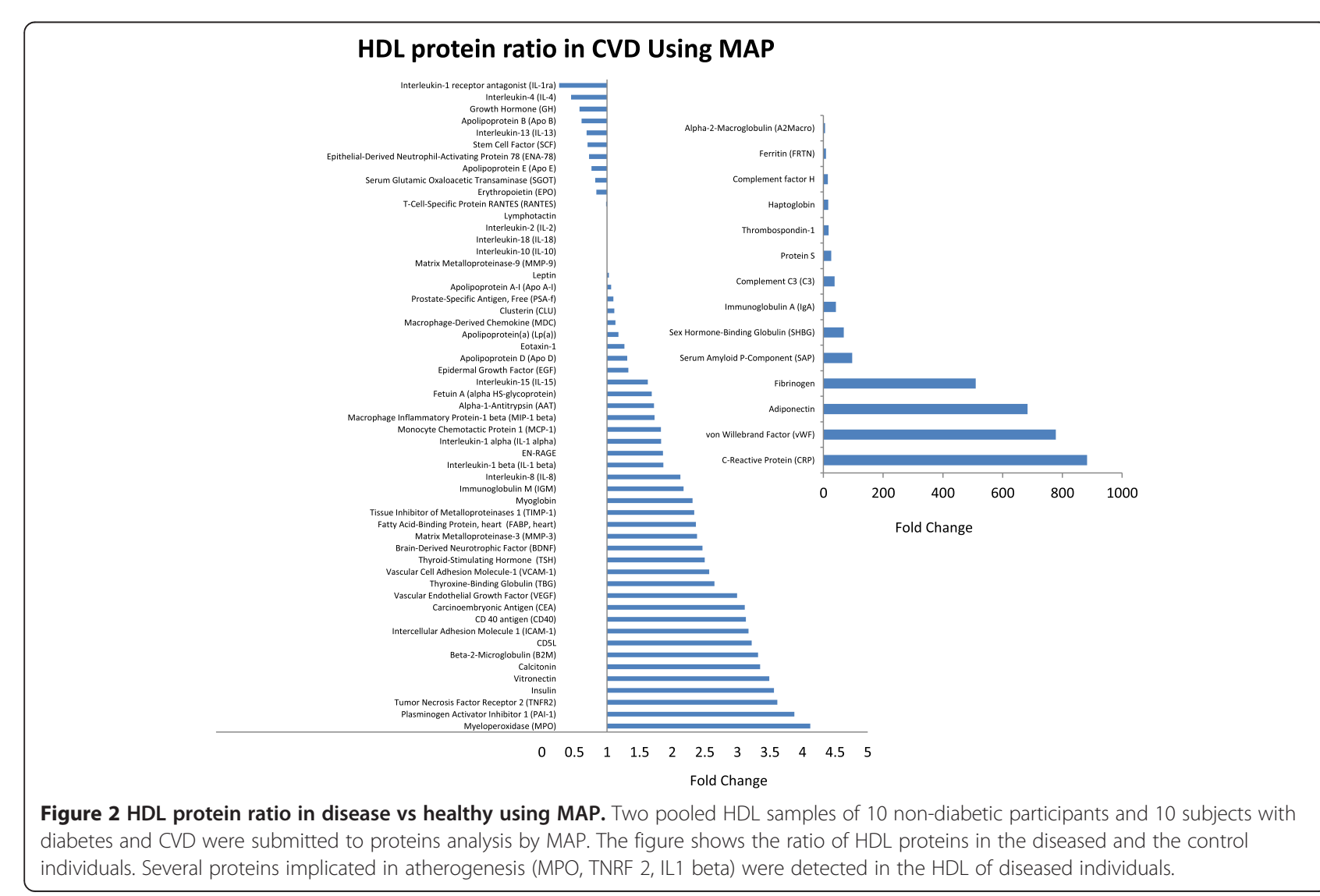


of this approach is limited. A larger study of subjects with and without disease is needed to fully characterize the distribution of these low abundance proteins on HDL. Unlike MAP, the sensitivity of MRM is limited without prior sample enrichment. Hence, the accuracy of the assay is compromised when sample concentrations fall below the linear range of the assay as evidenced by the increased coefficient of variation (CV) in several MRM proteins. By MRM, we targeted transitions of 56 proteins. We were able to detect 32 proteins of which 11 proteins had CVs less than 20\% on the replicate runs (Tables 1 and 2). Clusterin is a high abundant protein that is associated with HDL. We were able to quantitate clusterin accurately in plasma $(\mathrm{CV}<5 \%$ [6]); however we were not able to reliably measure it in HDL as was previously demonstrated [8] reflecting the challenges of using MRMs for protein quantification when levels of a given target falls out of the dynamic range in diseased states. Comparing HDL proteins in the CVD versus control pool by MRM revealed the depletion of several lipid metabolism proteins such as Apo CI, CII and PON-1 in CVD. In contrast, the concentrations of several acute phase proteins such as clusterin, Complement C9, alpha-1-antitrypsin were increased in CVD (Figure 3).
These findings would facilitate conducting larger studies using the presented approach to examine the effect of inflammation and atherosclerosis associated proteins on HDL composition and function in individuals with diabetes and CVD.

\section{Challenges of measuring lipid associated proteins}

Measurement of lipid associated proteins has been successful using immunoassays based on nephelometry and mass spectrometry $[1,4,8]$. Nephelometry is not widely available and not amenable to multiplexing. Conventional mass spectrometry techniques using spectral counting or extracted ion chromatograms can be lengthy and challenging in large sample sizes. Here, we present two alternatives (MAP and MRM) that are amenable to multiplexing, and are high throughput. MAP is limited by the availability and quality of pre-exiting antibody panels. MRM, on the other hand, can lose sensitivity at the lower end of abundance. Although the performance of MRM in lower abundance HDL proteins was inferior to immune based assays, the performance of MRM is likely to improve with the development of more sensitive mass spectrometry analyzers and better sample fractionation methods.

\section{HDL protein ratio in CVD Using MRM}

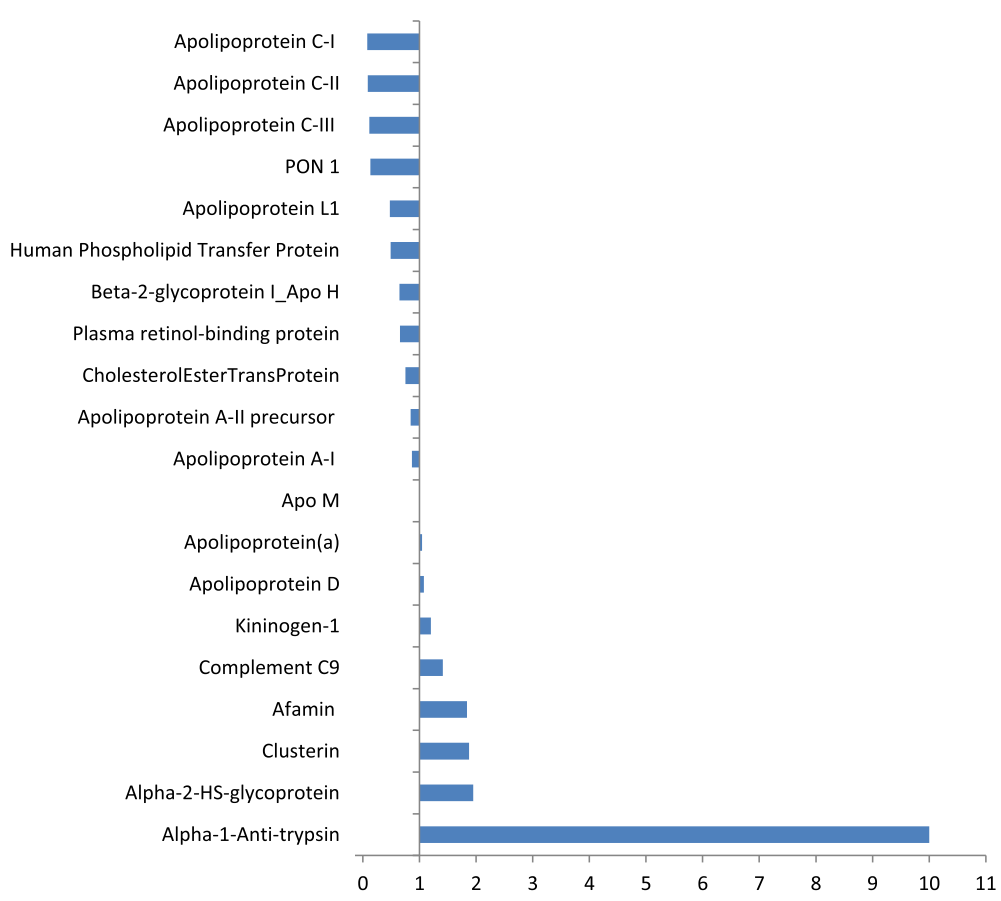

Figure 3 HDL protein ratio in disease vs healthy using MRM. Two pooled HDL samples of 10 non-diabetic participants and 10 subjects with diabetes and CVD were submitted to proteins analysis by MRM. The figure shows the ratio of HDL proteins in the diseased and the control individuals using MRM. Proteins involved in lipid metabolism were decreased whereas proteins involved in inflammation were increased on HDL of participants with CVD. 


\section{Limitations}

There are several limitations of this study. First, the present study was done with two pools of clinical samples. As such, the present work describes an alternative analytical tool for the measurement of HDL proteins. Application of these assays to larger clinical data sets is feasible and will allow determination of their clinical utility. Second, the digestion efficiency of each protein monitored by MRM was not assessed. However, we have previously shown [19] that if the digestion procedure is consistent and reproducible, then the ability to compare quantitative values between samples is maintained. Thus, the results presented are better described as "relative accurate abundances". Despite this limitation, several peptides quantitated by MRM were correlated with measurement using MAP (Table 5) affirming our claim that the MRM assay can provide absolute quantitation. A third limitation of this study is that we did not use an independent method of HDL isolation (such as reciprocal co-immunoprecipitation of a given protein with Apo A-I, or gel filtration as suggested by Davidson et al. [20]) to validate that presence of these low abundance proteins on HDL. However, HDL isolated by a longer centrifugation step had successfully depleted albumin with several of the low abundance proteins still detectable on HDL. In addition, the proteins on HDL and the corresponding plasma concentrations did not correlate, whereas the two HDL fractions were highly correlated. This finding suggests that these low abundance proteins were not contaminant plasma proteins. Our findings however, need to be replicated in a larger study group.

\section{Conclusions}

This study suggests the feasibility of measuring HDL proteins using MRM and MAP. The application of MAP and MRM to the HDL proteome offers the potential to improve our understanding of HDL functions and help direct interventions aimed at remodeling the HDL phenotype in diabetes and CVD.

\section{Additional file}

Additional file 1: lists (1) details of MRM method summary.

(2) Table S1. showing the HDL protein concentrations after 12 dilutions for determination of lower limit of detection (linearity analysis) (3) Table S2. listing all the transitions used to screen for HDL proteins (4) Figure S1.

showing representative chromatograms from the 4 replicate runs.

\section{Abbreviations}

HDL: High density lipoprotein; CVD: Cardiovascular disease;

Apo A-I: Apolipoprotein A1; MRM: Multiple reaction monitoring;

MAP: Multi-analyte profiling.

\section{Competing interests}

The author's declare that they have no competing interests.

\section{Authors' contributions}

Participated in research design: HY, SL, DS, CB, DB; conducted experiments: $H Y, H K, A J$; performed data analysis and interpretation: HY, DB; contributed to the writing of the manuscript: $P R, C B$; critically revised the manuscript: $P R$ all authors read and approved the final manuscript.

\section{Acknowledgements}

We would like to thank Genome Canada and Genome BC for Science and Technology Innovation Centre funding support. We thank Carol Parker for her assistance with writing the manuscript. We would also like to recognize Tyra J. Cross and Suping Zhang for the synthesis of all SIS peptides and Juncong Yang for exemplary technical support. We also thank Dr. George Tsaprailis with his assistance in running MRMs at the Arizona Proteomics Consortium. Finally, we would like to thank Jeffrey Freiser for his assistance with Myriad RBM HDL runs.

\section{Sources of funding}

Dr. Yassine was supported by K23HL107389, AHA12CRP11750017 and USC CTSI pilot UL1TR000130. The content is solely the responsibility of the authors and does not necessarily represent the official views of the National Institutes of Health. MRM mass spectrometric data were acquired by the Arizona Proteomics Consortium supported by NIEHS grant P30ES06694 to the Southwest Environmental Health Sciences Center (SWEHSC to Dr. Lau), $\mathrm{NIH} / \mathrm{NCl}$ grant P30CA023074 to the Arizona Cancer Center (AZCC), and by the $\mathrm{BIO} 5$ Institute of the University of Arizona.

\section{Author details}

'Department of Medicine, University of Southern California, Los Angeles, CA USA. ${ }^{2}$ University of Victoria - Genome British Columbia Proteomics Centre, Victoria, BC, Canada. ${ }^{3}$ Arizona State University, Tempe, AZ, USA. ${ }^{4}$ Statistics Consulting Laboratory, University of Arizona, Tucson, AZ, USA. ${ }^{5}$ Phoenix VA Health Care System, Phoenix, AZ, USA. ${ }^{6}$ Southwest Environmental Health Sciences Center, Department of Pharmacology and Toxicology, College of Pharmacy, University of Arizona, Tucson, AZ, USA. 'Department of Biochemistry and Microbiology, University of Victoria, Victoria, BC, Canada.

Received: 26 September 2013 Accepted: 26 December 2013

Published: 8 January 2014

\section{References}

1. Vaisar T, Pennathur S, Green PS, Gharib SA, Hoofnagle AN, Cheung MC, Byun J, Vuletic S, Kassim S, Singh P, et al: Shotgun proteomics implicates protease inhibition and complement activation in the antiinflammatory properties of HDL. J Clin Invest 2007, 117:746-756.

2. Hoofnagle AN, Wu M, Gosmanova AK, Becker JO, Wijsman EM, Brunzell JD, Kahn SE, Knopp RH, Lyons TJ, Heinecke JW: Low clusterin levels in high-density lipoprotein associate with insulin resistance, obesity, and dyslipoproteinemia. Arterioscler Thromb Vasc Biol 2010, 30:2528-2534.

3. Alwaili K, Bailey D, Awan Z, Bailey SD, Ruel I, Hafiane A, Krimbou L, Laboissiere S, Genest J: The HDL proteome in acute coronary syndromes shifts to an inflammatory profile. Biochim Biophys Acta 1821, 2012:405-415.

4. Green PS, Vaisar T, Pennathur S, Kulstad JJ, Moore AB, Marcovina S, Brunzell J, Knopp RH, Zhao XQ, Heinecke JW: Combined statin and niacin therapy remodels the high-density lipoprotein proteome. Circulation 2008, 118:1259-1267.

5. Anderson L, Hunter CL: Quantitative mass spectrometric multiple reaction monitoring assays for major plasma proteins. Mol Cell Proteomics 2006, 5:573-588.

6. Kuzyk MA, Smith D, Yang J, Cross TJ, Jackson AM, Hardie DB, Anderson NL, Borchers $\mathrm{CH}$ : Multiple reaction monitoring-based, multiplexed, absolute quantitation of 45 proteins in human plasma. Mol Cell Proteomics 2009, 8:1860-1877.

7. Addona TA, Abbatiello SE, Schilling B, Skates SJ, Mani DR, Bunk DM, Spiegelman $\mathrm{CH}$, Zimmerman $\sqcup$, Ham AJ, Keshishian $\mathrm{H}$, et al: Multi-site assessment of the precision and reproducibility of multiple reaction monitoring-based measurements of proteins in plasma. Nat Biotechnol 2009, 27:633-641.

8. Hoofnagle AN, Becker JO, Oda MN, Cavigiolio G, Mayer P, Vaisar T: Multiple-reaction monitoring-mass spectrometric assays can accurately 
measure the relative protein abundance in complex mixtures. Clin Chem 2012, 58:777-781.

9. Boden WE, Probstfield JL, Anderson T, Chaitman BR, Desvignes-Nickens P, Koprowicz K, McBride R, Teo K, Weintraub W: Niacin in patients with low HDL cholesterol levels receiving intensive statin therapy. N Eng/ J Med 2011, 365:2255-2267.

10. Nissen SE, Tardif JC, Nicholls SJ, Revkin JH, Shear CL, Duggan WT, Ruzyllo W, Bachinsky WB, Lasala GP, Tuzcu EM: Effect of torcetrapib on the progression of coronary atherosclerosis. N Engl J Med 2007, 356:1304-1316.

11. Schwartz GG, Olsson AG, Abt M, Ballantyne CM, Barter PJ, Brumm J, Chaitman BR, Holme IM, Kallend D, Leiter $L A$, et al: Effects of dalcetrapib in patients with a recent acute coronary syndrome. N Engl J Med 2012 367:2089-2099.

12. Carson RT, Vignali DA: Simultaneous quantitation of 15 cytokines using a multiplexed flow cytometric assay. J Immunol Methods 1999, 227:41-52.

13. Arellano-Garcia M, Hu S, Wang J, Henson B, Zhou H, Chia D, Wong D: Multiplexed immunobead-based assay for detection of oral cancer protein biomarkers in saliva. Oral diseases 2008, 14:705-712.

14. Morgan E, Varro R, Sepulveda H, Ember JA, Apgar J, Wilson J, Lowe L, Chen R, Shivraj L, Agadir A: Cytometric bead array: a multiplexed assay platform with applications in various areas of biology. Clin Immunol 2004, 110:252-266.

15. Yassine H, Borges CR, Schaab MR, Billheimer D, Stump C, Reaven P, Lau SS, Nelson R: Mass spectrometric immunoassay and MRM as targeted MS-based quantitative approaches in biomarker development: Potential applications to cardiovascular disease and diabetes. Proteomics Clin Appl 2013, 7:528-540.

16. Scanu AM, Fless GM: Lipoprotein (a). Heterogeneity and biological relevance. J Clin Investig 1990, 85:1709.

17. DRAYNA DT, MCLEAN JW, WION KL, TRENT JM, DRABKIN HA, LAWN RM: Human Apolipoprotein D Gene: Gene Sequence, Chromosome Localization, and Homology to the a2u-Globulin Superfamily. Dna 1987, 6:199-204.

18. Niederkofler EE, Tubbs KA, Kiernan UA, Nedelkov D, Nelson RW: Novel mass spectrometric immunoassays for the rapid structural characterization of plasma apolipoproteins. J Lipid Res 2003, 44:630-639.

19. Proc JL, Kuzyk MA, Hardie DB, Yang J, Smith DS, Jackson AM, Parker CE, Borchers CH: A quantitative study of the effects of chaotropic agents, surfactants, and solvents on the digestion efficiency of human plasma proteins by trypsin. J Proteome Res 2010, 9:5422-5437.

20. Davidson WS, Silva RA, Chantepie S, Lagor WR, Chapman MJ, Kontush A: Proteomic analysis of defined HDL subpopulations reveals particle-specific protein clusters: relevance to antioxidative function. Arterioscler Thromb Vasc Biol 2009, 29:870-876.

\section{Submit your next manuscript to BioMed Central and take full advantage of:}

- Convenient online submission

- Thorough peer review

- No space constraints or color figure charges

- Immediate publication on acceptance

- Inclusion in PubMed, CAS, Scopus and Google Scholar

- Research which is freely available for redistribution 